\title{
¿ES POSIBLE UNA TEORÍA UNITARIA Y CONSISTENTE DE LOS CAPÍTULOS DE LA CONSTITUCIÓN RELATIVOS A DERECHOS FUNDAMENTALES?*
}

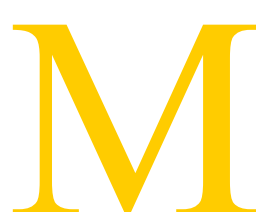

i respuesta a esta pregunta va a ser negativa. Pero naturalmente, sólo la plantea como hipótesis, y además al final de este trabajo, pienso que tal pregunta se convierte en una pregunta distinta, que por supuesto no va a ser mi intención responder. Por lo demás, en esta exposición voy a prescindir, por mor de la claridad en la argumentación, de muchos asuntos y problemas que vendrían al caso, de modo que también por este capítulo sólo puedo pretender para la respuesta negativa a la pregunta un carácter heurístico e hipotético.

Conviene hacer referencia a la historia de la pregunta. Se planteó inicialmente en el contexto de un seminario conjunto entre profesores de filosofía y de derecho acerca de los conceptos de igualdad y libertad en la Constitución Española. En un determinado momento fue inevitable abordar la cuestión de qué era lo que en realidad estábamos buscando. La respuesta parecía obvia: la teoría implícitamente contenida en la Constitución Española acerca de los conceptos de libertad e igualdad. Mi opinión fue que tanto la Constitución Española como cualquier otra del mismo tipo probablemente tendría que contener varias. Lo único que pretende es exponer las razones de tal opinión.

Esas razones me las confirma el libro de R. Alexy Theorie der Grundrechte (Frankfurt, 1986), en el que el autor pretende desarrollar una teoría jurídica, unitaria y consistente de los capítulos de la Grundgesetz alemana relativos a derechos fundamentales, y creo que no lo consigue; pero específicamente, a este libro sólo me referiré al final de este trabajo.

Lo que en este momento sí que me interesa subrayar, pues es metodológicamente importante, es lo siguiente: el que lo que se busque en nuestro contexto sea una teoría «jurídica»o «no jurídica»

\footnotetext{
* Este trabajo forma parte de un proyecto de investigación en curso subvencionado por el CSICYT.
} 
es algo que no tiene más trascendencia. Incluso podemos partir, como veremos al final, de la tesis positivista de que el derecho, es un edificio normativo que se sostiene sobre sí mismo. Si se tratase del «Fuero de los españoles», puede que el jurista pudiese extraer una teoría unitaria y consistente de los conceptos de libertad e igualdad de que allí se hace uso, teoría que le vincula como jurista o historiador del derecho político, pero que, en el caso normal, moralmente no comparte. Cuando se trata de una Constitución del tipo de la española, el lado normativo de la dogmática jurídica, es decir, de la teoría global que el jurista ha de construir para referirse con consistencia a (esos capítulos de) la Constitución, versa sobre principios que en el caso normal también el jurista moralmente comparte. La tesis es entonces que el jurista no puede dar a ese lado normativo de la dogmática la forma de una teoría unitaria y consistente. Y a su vez: supongamos que un grupo de ciudadanos (por ejemplo, los miembros del Tribunal Constitucional) ven perfectamente y exactamente reflejadas en los capítulos de derechos fundamentales de la Constitución Española lo que son sus convicciones ético-política. La respuesta negativa a la pregunta inicial viene a significar que tales convicciones no pueden ser reducidas a una teoría unitaria y consistente que resultase lógicamente vinculante para todos ellos.

\section{II}

\section{A) Núcleo normativo de la tradición liberal. «La promesa liberal.»}

Consideremos las formulaciones siguientes: «Para entender correctamente el poder político, y derivarlo de su fuente, tenemos que considerar en qué estado estaban los hombres naturalmente, y ese estado es un estado de perfecta libertad para ordenar sus acciones y disponer de sus posesiones y de sus personas como consideren adecuado dentro de los límites de la ley natural, sin tener que pedir permiso ni depender de la voluntad de otro hombre... un estado de perfecta libertad en el que el poder y la jurisdicción son recíprocos... y como a todos los hombres puede impedírseles que invadan los derechos de los demás y se les puede obligar a cumplir la ley natural, en ese estado la ejecución de la ley de la naturaleza queda puesta en manos de todos y de cada uno, lo que significa que todos y cada uno tienen derecho a castigar a los transgresores de la ley natural en un grado en que se impida su violación... Aunque la Tierra y todas las 
criaturas inferiores sean propiedad de todos los hombres, sin embargo cada cual tiene la propiedad de su propia persona. Sobre la persona de cada uno ningún otro tiene derecho si no es él mismo. El trabajo de su cuerpo y la obra de sus manos son propiedad suya... y aquello con que mezcle su trabajo es incuestionablemente propiedad del que trabaja, nadie sino él tiene derecho a lo que se ha anexionado por el trabajo, «at least where there is enough and as good left in common to others» ${ }^{1}$.

Voy a llamar a estas ideas «núcleo normativo» de la tradición liberal en sentido estricto.

La tradición liberal, de Locke a Hayek, y, en cualquier caso, con toda claridad desde A. Smith en adelante, consta del núcleo normativo que he mencionado y de un supuesto fáctico. Ambos conjuntamente constituyen lo que podemos llamar la «promesa liberal». El liberalismo clásico añade a su núcleo normativo la suposición de que el agregado resultante de todas las acciones atenidas a reglas de conducta justa (justas conforme a los principios enunciados por Locke) es capaz de estabilizarse por sí mismo, es decir, no genera disfunciones que reobren sobre el conjunto amenazando con hacerlo explotar. La afirmación de este supuesto permite al liberalismo clásico contar con una totalidad en la que no es menester intervenir, o mejor aún, la intervención en la cual sería por un lado injusta, pues no podría hacerse sino mediante reglas ad hoc que violarían el necesario carácter general de las reglas de conducta justa $y$, por otro, disfuncional, pues generaría desequilibrios que acabarían redundando en perjuicio de todos.

En 1936, en su Teoría general del interés, la ocupación y el dinero, Keynes, retomando la discusión Ricardo/Malthus, pone en cuestión este supuesto fáctico que es parte esencial de la «promesa liberal». Uno de los derroteros tomados tras Keynes por esa tradición se atiene a la «promesa liberal»; el otro se atiene a su «núcleo normativo» y prescinde de la promesa. La primera posición viene ejemplarmente representada en nuestros días por el pensamiento político de Hayek. Representante de la segunda es Anarchy, State and Utopia, de R. Nozick.

Examinemos brevemente la línea que se atiene a la «promesa liberal». ¿Qué ocurre si ese supuesto fáctico no se cumple? La respuesta de Hayek es negar tal posibilidad. Al enfrentarse a la idea keynesiana de que el volumen de empleo es función de la

${ }^{1}$ J. Locke, Second Treatise on Government, Oxford, 1980, págs. 290 ss. 
demanda global, que compete a los gobiernos o administraciones manipular con el fin de obtener el volumen de empleo que se desee, comenta Hayek: «Esta fórmula del empleo como función directa de la demanda total resultó ser extraordinariamente efectiva porque parecía venir confirmada en cierto grado por los resultados de los datos empíricos cuantitativos, mientras que las consideraciones alternativas del desempleo que yo considero correctas no pueden pretender tal cosa... nos encontramos aquí con que la teoría que mejor puede ser confirmada por las estadísticas porque es la única que puede ser confirmada estadísticamente, es, sin embargo, falsa y ha sido ampliamente aceptada porque las explicaciones que antes se consideraban verdaderas y que yo sigo considerando verdaderas, por su propia naturaleza no pueden comprobarse en esos términos... La causa del desempleo es una desviación de los precios y salarios respecto de su posición de equilibrio, que se establecería por si misma en un mercado libre y con moneda estable. Pero nosotros nunca podemos saber con qué sistema de precios y salarios relativos el equilibrio se establecería por sí mismo. Por tanto, el que desde mediados de los años setenta se haya producido un desempleo sustancial no es efecto del fracaso del capitalismo, de la economía de mercado, sino exclusivamente de nuestros errores, que la experiencia pasada y el conocimiento adquirido nos deberían haber llevado a evitar», pues «el sueño de Keynes es un sueño que se ha muerto, aunque su fantasma pueda seguir apestando la política durante décadas». "Sir J. Hicks ha propuesto incluso que llamemos al tercer cuarto de este siglo (1945-75) la era de Keynes como el segundo cuarto fue la era de Hitler. No creo -añade benévolamente Hayek- que el daño que personalmente hizo Keynes merezca tal descripción, pero en la medida en que sus recetas parecieron funcionar crearon una ortodoxia a la que pareció inútil oponerse»; Keynes «fue, sin duda, un hombre de gran cabeza, pero de escasos conocimientos de economía» ${ }^{2}$.

Esta reformulación contemporánea de la tradición liberal se limita a reiterar la «promesa liberal». Al hundimiento de la economía keynesiana desde principios de los años setenta, al hundimiento del «sueño de Keynes», no tiene otra cosa que oponerle que la «ley de Le Say» entendida como artículo de fe. La aceptación de este artículo de fe se nos torna hoy difícil, pues disponemos de teorías alternativas para explicar por qué, al menos en el plano de las economías nacionales, el sueño de Keynes se ha

${ }^{2}$ F. A. Hayek, New Studies, London, 1974, págs, 163 ss. 
muerto para siempre. Me refiero, por ejemplo, a teorías como las de Frôbel, a las que me referiré después. No se cumplen, dada la «nueva división internacional del trabajo», las condiciones de una «economía nacional» como sistema razonablemente cerrado, cuyas variables determinantes pudieran seguir siendo manipuladas por los gobiernos. Aceptar de esta reformulación del liberalismo clásico que el sueño de Keynes ha muerto, no implica negar que Keynes nos despertara, quizá definitivamente también, del sueño liberal. La segunda reformulación hoy más llamativa de la tradición liberal prescinde de este supuesto fáctico del liberalismo clásico, de la ley de Le Say, y se atiene exclusivamente a lo que he llamado «núcleo normativo» de la tradición liberal; se trata de la reformulación que de ese «núcleo normativo» lleva a cabo R. Nozick en Anarchy, State and Utopia ${ }^{3}$, que por su carácter típico ideal considero una obra fundamental del pensamiento ético-político del pasado decenio, una obra que, por lo demás, hoy ha crecido en importancia.

En A Theory of Justice, a la hora de justificar el «principio de la diferencia», Rawls había procedido declarando los «natural assets» como arbitrarios desde un punto de vista moral. Nadie ha merecido su mayor capacidad natural ni tampoco ha merecido un punto de partida más favorable en la sociedad. Y siendo esto así, el «principio de la diferencia» que se elige en la «posición original» representa un acuerdo relativo a mirar la distribución de los talentos naturales y de las diversas posiciones de partida en la sociedad como un «asset común» y a participar en los beneficios de esa distribución natural y aleatoria. Así, conforme al «principio de la diferencia», los que han sido favorecidos por la naturaleza y por la «suerte», pueden obtener beneficios de su buena fortuna, pero sólo a condición de que ello mejore la situación de aquellos que quedan en peor posición ${ }^{4}$.

Nozick se enfrenta a esta idea de Rawls de una forma singular. No puede negar que, en efecto, nadie ha merecido las dotes naturales con que ha nacido. Pues bien, si se destruye teoréticamente la idea de «comunidad política», el único depositario de esas dotes sólo puede ser el individuo que es portador de ellas. Nozick emprende esta maniobra contra Rawls, a la vez que una radicalización de la posición liberal clásica, efectuando una lectura de Locke, en la que, ciertamente, ese Locke reformulado resulta incluso más consecuente de lo que es en sí mismo.

${ }^{3}$ R. Nozick, Anarchy, State and Utopia, Oxford, 1974.

${ }^{4}$ Rawls, A Theory of Justice, Oxford, 1973, 251 ss. 
Como es de sobra sabido, en la construcción de Locke, es el problema de la exacción de justicia lo que lleva a que el individuo delegue las funciones de juez y ejecutor de la ley natural que le competen en el estado de naturaleza. Y ello por vía de un «contrato» por el que se constituye una «commonwealth» un «cuerpo político». En este punto hay una coincidencia formal tanto con la tradición de la Política clásica, como con la tradición de pensamiento democrático en sentido estricto a la que después me voy a referir. Se diría que también la tradición liberal admite una esfera de contrato, consenso, acuerdo, sometido a condiciones normativas, que constituiría lo específico de la «esfera política». Es en la determinación de esas condiciones normativas, en donde se separarían la tradición de la política clásica (desde Aristóteles hasta la teoría de la «societas civilis, seu res publica, seu communitas politica» de la Escolástica tardía), la tradición liberal y la tradición democrática moderna. Pues bien, en la reformulación que del «núcleo normativo» de la tradición liberal hace Nozick queda de manifiesto, que de atenernos a ese núcleo normativo, tal momento de acuerdo es prescindible y que podemos reconstruir (o si se quiere deconstruir) consistentemente a partir de los «derechos lockeanos» y sin hacer mención a contrato alguno, el orden de lo político; a la vez, esta reconstrucción se convierte, desde una perspectiva rigurosamente atenida a ese núcleo normativo, en instancia crítica de las formas de organización política vigentes.

Los pasos de la reconstrucción de Nozick son bien simples. Partimos del individuo rodeado de la «circunferencia moral» que representan los derechos lockeanos. Si alguien viola sus derechos, el individuo puede hacer justicia él solo, u otros pueden unirse a él para hacer justicia. «Esto no viola los derechos lockeanos de nadie» (es la condición a la que ha de ajustarse cada paso de la construcción). Segundo paso: las ventajas que ofrece la división del trabajo harán que determinadas personas se especialicen en ofrecer servicios de protección, fundarán una «agencia protectora». Tampoco eso viola los derechos lockeanos de nadie. Tercer paso: en caso de conflicto entre los clientes de una misma agencia, éstos podrán transferir a la agencia el derecho a decidir si ha habido violación de derechos y hasta qué punto; las agencias, por motivos de racionalidad económica, podrán exigir tal transferencia como condición para poder contratar sus servicios; tampoco esto viola los derechos lockeanos de nadie. Cuarto paso: ¿qué ocurre en caso de conflicto entre clientes de diferentes agencias? Si las agencias están de acuerdo, nada especial. Si no lo están, o bien una acabará dominando sobre las otras, es decir, 
se producirá la situación que describiré después en lo tocante a la relación de la agencia con el independiente, o bien se constituirá un sistema judicial federal unificado». Y así tendríamos en un área geográfica, sin que se hubieran violado los derechos lockeanos de nadie, y sin que haya mediado «contrato social» alguno (es decir, sin que el individuo haya transferido de sus competencias en el «estado de naturaleza» absolutamente nada más que lo que es menester para la protección de sus derechos) algo parecido a un «minimal State». Mas tal «Estado» no parece ser aún un Estado, pues le falta la nota weberiana de «monopolio de la violencia legítima» y protección de los derechos de todos. Quinto paso: Consideremos la cuestión de las relaciones de la agencia con los independientes, es decir, con aquellos que no han contratado los servicios de ninguna agencia. Supongamos que un independiente, ante una supuesta violación de sus derechos, exige lo que a juicio de la agencia que el transgresor tiene contratada representa una compensación desmedida o que viola los derechos de terceros, o que la agencia considera que el independiente se dispone a exigir justicia por procedimientos que la agencia no juzga fiables o equitativos. La agencia puede prohibirle o impedirle la acción que el independiente proyecta. La razón que da la agencia al no cliente para prohibirle su acción es que ésta implica un grave peligro de que se violen los derechos lockeanos de su cliente o los derechos lockeanos de terceros (pues en el «estado de naturaleza», todos, también las agencias, son «jueces y ejecutores de la ley natural»).

Tenemos, por tanto, que la agencia considera sus procedimientos fiables y equitativos $y$, por otro, que todos tienen derecho a defenderse de procedimientos que no consideren que son fiables y equitativos. Ahora bien, como la agencia considera que sus procedimientos lo son y que ello es evidente, no permitirá que nadie los contravenga. Castigará a los que lo hagan. De ahí, concluye Nozick, que aunque la agencia ni pretenda ni pueda pretender un monopolio, su posición será única en virtud de la facticidad de su poder. No existe un derecho que la «agencia protectora dominante» pueda pretender poseer en exclusiva para imponer un derecho particular. Pero la naturaleza del derecho es tal, que una vez que un poder dominante emerge, sólo él lo ejercitará de hecho. Pues el derecho incluye el derecho a evitar que otros lo ejerzan erróneamente y sólo el poder dominante será capaz de ejercer ese derecho sobre todos los otros.» ${ }^{5}$. Es decir,

${ }^{5}$ J. Nozick, Ibid., 55 ss. 
todos tienen el derecho que sólo la agencia protectora dominante podrá de hecho ejercitar. Tras una discusión sobre el «status moral dentro del estado de naturaleza de los derechos procedimentales y de la prohibición de las actividades peligrosas y del status de hacer valer por la fuerza sus propios derechos», Nozick llega a la conclusión de que por tal interferencia (justificada) en los derechos lockeanos del independiente, los clientes (la agencia) (prescindimos aquí, por mor de la brevedad, del caso de las relaciones entre independientes) ha de compensar al independiente por la desventaja en que queda puesto. La forma menos costosa es la de ofrecerles servicios protectores para cubrir las situaciones de conflicto con los clientes de la agencia. Tenemos, pues, una «agencia protectora dominante» con un monopolio, no de iure, sino de facto sobre la violencia legítima y que protege los derechos de todos, y todo ello sin que se hayan violado los derechos lockeanos de nadie.

Pues bien, un Estado con más facultades que este «minimal state» representa una intromisión ilegítima en la circunferencia moral que rodea al individuo y que define el único sentido en que los individuos son iguales y libres.

No deja de ser inquietante la situación en que en esta construcción queda el poder: la facticidad del poder queda aquí elevada a categoría, en esta reformulación de su núcleo normativo la tradición liberal viene a dar en las proximidades de Hobbes. Y la razón de ello, como después mostraré, es clara: al acercarse a la cuestión de la estructura del poder la tradición liberal se enfrenta a un problema que en la historia del pensamiento político moderno no ha sido nunca el suyo; aquí, al abordarlo directamente, la tradición liberal deja de nuevo suelto ese poder.

B) Núcleo normativo de la tradición de pensamiento democrático. La "promesa democrática»

«La soberanía nacional reside en el pueblo español del que emanan los poderes del Estado» (Constitución Española, art. 1,2).

A la tradición liberal le son ajenos los conceptos de soberanía, pueblo y nación, y en rigor incluso el concepto de Estado. De modo que para obtener noticias del «pueblo soberano» hemos de recurrir a un capítulo bien distinto de la historia del pensamiento político, a lo que se inicia para el pensamiento moderno en El contrato social, de J. J. Rousseau.

Los primeros capítulos de El contrato social, de Rousseau, pueden leerse como un equivalente del Primer tratado sobre el Gobierno Civil, de Locke, como equivalente de la polémica de 
Locke con Filmer; y en todo caso también ha de tenerse en cuenta que también el Segundo tratado se entiende a sí mismo como una crítica contra la «tiranía».

Sin embargo, Rousseau no cuenta con un «interés general» de tipo adscrito en virtud de una «ley natural» y que la estructura jurídica de la asociación política hubiera de limitarse a sancionar y a proteger. Para Rousseau, la ley, toda ley, es un «acto de la voluntad general», es decir, de la «voluntad racional», la cual, como de Rousseau recogerá Kant, se define por su «autonomía y universalidad». Sólo en una forma de asociación que la realice puede recobrar el hombre (tras haberse adensado la red de relaciones sociales corruptas que acabaron para siempre con su libertad natural) la forma de libertad que le es condigna.

Se trata de una forma de asociación «que defienda y proteja con toda la fuerza común la persona y los bienes de cada asociado y por la cual cada uno, uniéndose a todos, no se obedece más que a sí mismo». Y el pacto del que esa asociación resulta, «si se le quita todo lo que no es de su esencia, se hallará que se reduce a los siguientes términos: cada uno pone en común su persona y todas sus energías bajo la dirección suprema de la voluntad general; y recibimos a cada uno como parte indivisible del todo». "Al instante -añade Rousseau- en lugar de la persona particular de cada contratante, este acto de asociación produce un cuerpo moral y colectivo, compuesto de tantos miembros como voces tiene la asamblea, la cual recibe de este acto su unidad, su yo común, su vida y su voluntad. Esta persona pública que así se forma por unión de todas las otras tornaba en otro tiempo el nombre de polis, y ahora toma el nombre de república o cuerpo político, el cual es llamado por sus miembros Estado cuando es pasivo, soberano cuando es activo, potencia cuando se lo compara a sus semejantes. En lo que se refiere a sus asociaciones toman colectivamente el nombre de pueblo, y se llaman en particular ciudadanos como participantes en la autoridad soberana, y súbditos en cuanto sometidos a las leyes del Estado.»

Pues bien, «la soberanía es el ejercicio de la voluntad general» y esta voluntad general «es siempre recta y tiende a la utilidad pública: mas de ello no se sigue que las deliberaciones del pueblo tengan siempre la misma rectitud. Uno quiere siempre su bien, mas no lo ve siempre. Nunca se corrompe al pueblo, mas a menudo se le engaña, y es entonces cuando parece querer lo que es malo. Pues con frecuencia hay diferencia entre la voluntad de todos y la voluntad general; es decir, esta última no tiene por objeto sino el bien general, la otra tiende al interés privado y no es sino la suma de intereses particulares». 
$\mathrm{Y}$ en lo que se refiere a los límites del poder soberano: «Lo convenido es que todo lo que uno aliena por el pacto social de su poder, bienes y libertad sea solamente la parte de todo ello cuyo uso importa a la comunidad, mas es también menester convenir en que sólo el soberano es juez en lo que respecta a esa importancia. Todos los servicios que un ciudadano puede hacer al Estado, se los hace en cuanto el soberano se los pide; pero el soberano no puede echar sobre sus súbditos ninguna carga inútil a la comunidad, ni siquiera puede quererlo: porque bajo la ley de la razón nada se hace sin su causa, así como tampoco bajo la ley de la naturaleza» ${ }^{6}$.

Ahora bien, consideremos formulaciones como la siguiente: «Cuando digo que el objeto de la ley es siempre general, entiendo que la ley considera a los sujetos en general y a las acciones como abstractas, jamás a un hombre como individuo ni a una acción particular. Así, la ley puede muy bien establecer que existan privilegios, mas no los puede conceder nominalmente a nadie; la ley puede incluso establecer distintas clases de ciudadanos, señalar incluso las cualidades que darán derecho a pertenecer a una de esas clases, pero no puede nombrar a tal o cual ciudadano para ser admitido en esas clases; puede establecer un gobierno real o una sucesión hereditaria, mas no puede elegir a un rey ni a una familia real; en una palabra, toda función que se refiera a un objeto individual no puede pertenecer al legislativo. Partiendo de esta idea se ve al instante que no hace falta ni preguntar a quien corresponde hacer las leyes, puesto que son actos de la voluntad general; ni si el príncipe (el gobierno) está por encima de las leyes, pues el príncipe es un miembro del Estado; ni si la ley puede ser injusta, pues nadie puede ser injusto para consigo mismo, ni cómo se puede ser libre y a la vez sujeto a leyes, pues las leyes no son sino registros de nuestras voluntades... el pueblo sometido a leyes debe ser el autor de ellas; el regular las condiciones de la sociedad es competencia de aquellos que se asocian... el pueblo quiere siempre el bien, pero no ve siempre ese bien. La voluntad general es siempre correcta, mas el juicio que la guía no es siempre ilustrado, es menester hacerle ver los objetos tales como son, a veces tales como deben parecerles, mostrarle el buen camino que busca, garantizarlo contra la seducción de las voluntades particulares. Los particulares quieren el bien que a veces rechazan, el público quiere el bien que no llega a ver. Todos tienen igualmente necesidad de guía.

${ }^{6}$ J. J. Rousseau, Du Contrat Social, París, 1972, pág. 65. 
Es menester obligar a los unos a conformar sus voluntades a su razón; hace falta enseñar al otro a conocer lo que quiere» ${ }^{7}$.

Es decir, por un lado, para la tradición de pensamiento democrático es esencial la distinción entre «voluntad de todos» y «voluntad general». Por otro, cuando tal distinción se establece, como lo hace o tiende a hacerlo Rousseau, en términos «sustancialistas» la tradición democrática atrae sobre sí, y con muy buenas razones, las sospechas de totalitarismo. Pero no es mi propósito ponerme a moralizar aquí contra «dictaduras educativas» o de cualquier otro tipo, que pudieran apelar a la tradición de pensamiento democrático, pues me basta señalar que tal interpretación «sustancialista» (por llamarla de algún modo) del concepto de voluntad general resulta insostenible ante el pensamiento ético contemporáneo que, vía Kant, se remite a Rousseau.

Las reformulaciones contemporáneas de la ética de Kant trazan la distinción entre ambos conceptos interpretando la universalidad de la norma, no en términos semánticos como en el texto alegado hace Rousseau, sino en términos procedimentales. Fácticamente no hay nunca más que voluntad de todos (en el mejor de los casos). Voluntad general no puede ser sino la presunción de racionalidad que asiste a una voluntad de todos. La voluntad general es el momento ideal, contrafáctico, operante en la voluntad de todos, en la medida en que esta última se haya obtenido en unas condiciones que hayan permitido poner en juego todos los argumentos y se mantengan unas condiciones que permitan a todos argumentar, revisar y volver sobre lo decidido. Voluntad general no puede ser, pues, sino la presunción de racionalidad que asiste a la voluntad de todos en virtud del procedimiento por el que ha sido obtenida y por el que, eventualmente, se la someta a revisión.

Recurramos, por ejemplo, a la reformulación que en términos procedimentales hace Habermas de la ética kantiana, remitiéndose expresamente a Rousseau. ¿Cuáles son las condiciones que ha de cumplir una situación de deliberación para que la decisión resultante de ella pueda considerarse racional? La respuesta de Habermas es: la de una «situación ideal de habla». Las «situaciones ideales de habla» cumplen ante todo dos condiciones, que en cierto modo pueden considerarse triviales. Primera: todos los participantes potenciales en un proceso de deliberación tienen que tener las mismas oportunidades de emplear «actos de

${ }^{7}$ Ibid., págs. 77 s. 
habla comunicativos», de forma que en todo momento puedan iniciar un discurso, así como perpetuarlo por medio de preguntas y respuestas, de réplicas y contrarréplicas. Segunda: todos los participantes en el proceso de deliberación (ya, pues, dentro del proceso de deliberación) tienen que tener la misma oportunidad de hacer afirmaciones, interpretaciones, propuestas, de dar explicaciones y de hacer justificaciones, de fundamentar y de refutar, de modo que a la larga ningún prejuicio quede sustraído a la tematización y a la crítica.

Algo menos triviales son otras dos condiciones, que no se refieren tanto a los procesos de deliberación como a la situación en que los deliberantes potenciales se hayan en los contextos de acción. Tercera: «Para el discurso sólo se permiten hablantes que, como actores, tengan las mismas oportunidades de emplear actos de habla representativos, es decir, de dar expresión a sus actitudes, sentimientos e intenciones. Pues sólo la recíproca sintonización de los espacios de expresión individual y el juego de proximidad y distancia en los contextos de acción pueden garantizar que los agentes, también cuando participan en un proceso de deliberación se comporten con veracidad respecto a sí mismos y hagan transparente su naturaleza interna.» Cuarta: «Para el discurso sólo se permiten hablantes que, como actores, tengan iguales oportunidades de emplear actos de habla regulativos, es decir, de ordenar y de oponerse, de permitir y de prohibir, de prometer y retirar promesas, de dar cuenta y de exigirla, etc. Pues sólo la reciprocidad completa de expectativas de comportamiento, que excluye los privilegios en el sentido de normas de acción o de valoración unilateralmente obligatorias, garantizan que la equidistribución formal de las propiedades de abrir un discurso y de proseguirlo se van a emplear también de hecho para dejar en suspenso las coacciones de la realidad y entrar en el ámbito libre de experiencia y descargado de acción, que el discurso representa ${ }^{8}$.

Y, ¿por qué estas condiciones? Porque son las únicas capaces de asegurar la posibilidad de progresiva radicalización de un «nomos», radicalización que es a su vez la única capaz de movilizar el potencial de razones necesario para que el consenso pueda considerarse no un consenso cualquiera, sino un consenso fundado, no sólo una fáctica «voluntad de todos», sino una voluntad presuntivamente racional, es decir, una «voluntad general».

${ }^{8}$ J. Habermas, «Wahrheitstheorien» en Wirklichkeit und Reflexion, Pfullingen, 1973. 
Habermas señala distintos pasos en tal radicalización: «el primero consiste en el tránsito de los mandatos o prohibiciones problematizadas, que representan por su parte acciones (es decir, regulan un ámbito de acción) a la suspensión de su pretensión de validez controvertida, pretensión de validez que se convierte por tanto en objeto de deliberación (entrada en la deliberación). El segundo paso consiste en la justificación teorética del mandato o prohibición problematizados, es decir, en dar por lo menos un argumento en el sistema de lenguaje que se haya escogido, en el sistema de lenguaje, pues, en que de hecho estemos interpretando nuestras necesidades (discurso práctico). El tercer paso consiste en el tránsito a una modificación del sistema de lenguaje inicialmente escogido o a una ponderación de sistemas de lenguaje alternativos (discurso metaético o metapolítico). El último paso, que representa por tanto una ulterior radicalización, consiste en el paso a una reflexión acerca de la dependencia de la estructura de nuestras necesidades respecto del estado de nuestro saber y de nuestro poder: nos ponemos de acuerdo sobre las interpretaciones de nuestras necesidades a la luz de las informaciones de que disponemos acerca de lo que es factible y de lo que es alcanzable. A qué clases de informaciones hemos de darles preferencia en el futuro se convierte a su vez en una cuestión práctica, relativa por ejemplo a las prioridades en materia de política de fomento de la investigación. Pues en este nivel del discurso (de deliberación) se plantea la cuestión de qué debemos querer conocer» ${ }^{9}$.

En la doble exigencia de simetría (es decir, la exigencia relativa a las situaciones mismas de deliberación y la relativa a las situaciones de no deliberación, definidas ambas desde el proceso de deliberación) es donde radica el concepto democrático de igualdad y en el no estar sujeto sino a normas, a las que en las mencionadas condiciones asistan las «best reasons everyone can have» (K. Baier) radica el concepto democrático de libertad, o autonomía.

Si ello es así, podemos decir que las reformulaciones contemporáneas de la ética de Kant, al menos las que proceden en términos procedimentales, representan una reformulación de lo que he llamado «núcleo normativo» de la tradición democrática.

Pero aquí se nos ofrece un problema, y de nuevo el caso de Habermas puede ser típico. Habermas viene protestando una y otra vez contra toda tentativa de interpretar su «ética del discurso»

\footnotetext{
${ }^{9}$ Habermas, ibid.
} 
como una teoría normativa de la democracia ${ }^{10}$. La razón en el caso de Habermas es más que clara. Habermas entiende «el discurso» como una continuación de la acción comunicativa «con otros medios», como «una forma de reflexión de la acción comunicativa». A este tipo de acción Habermas lo considera primario, y al resto como «derivados», es decir, como deducibles de ella por vía de abstracción de elementos que integran la «acción comunicativa». Pues, bien, no está dicho que «lo político» (por ejemplo, lo que sucede en un parlamento) tenga primariamente que ver con el tipo de acción que Habermas llama «comunicativa» ni por tanto, con la forma de reflexión de la acción comunicativa que representa «el discurso». Lo único que Habermas afirma es que los procesos de reproducción cultural, de integración social y de socialización de los individuos sólo pueden tener lugar de forma no patológica a través del medio que representan la acción comunicativa y su forma de reflexión. Qué tenga que ver «lo político» con la acción comunicativa y con su forma de reflexión dependerá por tanto (en la construcción de Habermas, se entiende) de lo que «lo político» tenga que ver con esos procesos y con el desarrollo normal o patológico de ellos.

Sea como fuere, al concepto de voluntad general, básico en la tradición de pensamiento democrático, difícilmente cabe darle hoy otro sentido. En nuestro contexto, pues, podemos entender la ética del discurso de Habermas como una reformulación del núcleo normativo de la «tradición democrática», reducida a puros elementos normativos (en el sentido de que abstrae por entero de todo elemento político-organizativo). Si resultara que tal núcleo normativo nada o muy poco tiene que ver en definitiva con «lo político», de ello no se seguiría sino que la tradición democrática de pensamiento político no contiene más que una (por lo demás peligrosa) ilusión, como siempre pensó la tradición de pensamiento liberal, que nunca supo muy bien qué hacer con la distinción de Rousseau entre voluntad de todos y voluntad general. En este aspecto Habermas ocupa una posición polarmente opuesta a la de Nozick.

${ }^{10}$ J. Habermas, «Replik», en A. Honneth, Kommunikatives Handeln, Frankfurt, 1986. 


\section{III}

Dialéctica de tradición liberal y tradición democrática en la historia de la constitucionalización de los derechos fundamentales

Estas dos tradiciones de pensamiento político, al menos en sus formulaciones clásicas, no se han quedado en puras abstracciones ético-políticas, sino que por vía de movimientos sociales que las hicieron suyas han determinado la historia de las constituciones modernas y contemporáneas, y por tanto si tal historia, al menos en parte, es un precipitado de ellas, de ambas, los capítulos de las constituciones modernas y contemporáneas, relativos a derechos fundamentales, difícilmente podrán ser reducibles a una teoría unitaria, sino que de uno o de otro modo habrán de representar algún tipo de compromiso entre estas dos fundamentales autocomprensiones de la modernidad política.

En lo que sigue, ateniéndome a Marshall ${ }^{11}$, y a Habermas ${ }^{12}$ voy a distinguir cuatro períodos en la historia de la constitucionalización de los «derechos fundamentales», que nos permitirán reconocer la diversa fuente que en cada caso tienen esos derechos, y el compromiso entre los principios políticos que los inspiran.

Naturalmente, tal intento no puede menos de comportar salvajes simplificaciones. La principal de ellas es la equiparación e incluso fusión que, al establecer estas cuatro etapas, voy a llevar a cabo de la historia de la constitucionalización de tales derechos en Inglaterra, en Estados Unidos y en Francia. Mas pienso que si se lee atentamente a Marshall, esta equiparación e incluso fusión pueden justificarse. Marshall distingue tres etapas en esa constitucionalización: constitucionalización de los «derechos civiles», constitucionalización de los «derechos políticos» y constitucionalización de los «derechos sociales». Insiste Marshal en que cuando se constitucionalizan los derechos políticos en el siglo XIX se inicia una guerra entre los derechos fundamentales incluidos en ese capítulo y el sistema económico asentado sobre derechos asimismo fundamentales incluidos en el primero. Voy a interpretar esta tensión de que habla Marshall refiriéndose a Inglaterra (sobre todo) y a Estados Unidos como estructuralmente equivalente a la que se hace explícita en la Revolución Francesa

${ }^{11}$ T. H. Marshall, Class, Citizanship and Social Class, New York, 1974.

12 J. Habermas, Teoría de la Acción Comunicativa, segundo tomo. 
e incluso ya en la propia declaración (francesa) de los derechos del hombre y el ciudadano de 1789. En cualquier caso si las simplificaciones que voy a introducir privan de plausibilidad a estas etapas como etapas históricas, aún mantienen su valor como "medio auxiliar» con el que introducir la tesis que trataré de establecer al final de ese trabajo.

Primera etapa: La emergencia de las monarquías absolutas y con ellas del Estado Moderno, significa la disolución de la relación tradicional entre religión (derecho sacro), política y derecho. Si las cuestiones trascendentes no son susceptibles de decisión, si no hay ninguna posibilidad de asentar el derecho sobre ninguna concepción compartida del mundo y del bien, la única fuente de la que puede dimanar el derecho es la voluntad del soberano. Este es, digámoslo así, el punto de partida: el papel pacificador de las monarquías absolutas respecto de las guerras de religión. Las tres dimensiones del derecho tradicional (derecho sacro, derecho consuetudinario y derecho «establecido» por el príncipe, pero entendido siempre como interpretación o reformulación del «buen derecho antiguo») quedan reducidas a la dimensión del derecho «puesto» por el príncipe. El sistema económico, que viene ejerciendo desde fines de la Edad Media una presión cada vez mayor sobre las ligaduras tradicionales a que está sometido puede levantarse libre por encima de los órdenes tradicionales (los cuales venían legitimados por la relación tradicional entre religión, política y derecho) a la vez que los somete a un proceso de disolución, que en su «Filosofía del Derecho» Hegel describe como «ruptura del mundo ético». De modo que, por este lado, bajo la monarquía absoluta tiene lugar la institucionalización del dinero como código de autogobierno (en el sentido en que hoy lo conocemos) de una economía no sujeta ya a ligaduras tradicionales. Las regulaciones jurídicas sobre que ese código se asienta son las del derecho privado en sentido moderno, que tienden a convertirse en las únicas relaciones normativas de los miembros de la sociedad entre sí. Si a esto unimos el reconocimiento (y posteriores transformaciones) por vía de hecho de las libertades subjetivas relativas a religión, creencias, pensamiento y por último expresión, tenemos la realidad o al menos el germen de buena parte de los «derechos civiles» que hoy nos son habituales. Naturalmente que en el Estado absoluto el derecho privado adquiere validez y vigencia de la sanción de que es objeto por parte del Soberano; de modo que, parafraseando a Niklas Luhman, cabe decir que tanto en el derecho privado (en principio) como (sobre todo) en el derecho público la «arbitrariedad» («notre bon plaisir») queda elevada a institución, 
pero el desarrollo del sistema económico domestica al «poder»; el sistema económico necesita de un derecho público susceptible de previsión y cálculo, y obliga a la racionalización y estabilización de un sistema complementarlo ya por demás en proceso de formación merced a otro género de imperativos (militares), el sistema que representa la administración estatal, y esta administración, por imperativos de eficiencia, no tiene más remedio que imponer un tratamiento igual (en ámbitos de la existencia que empiezan a ser cruciales) de casos iguales, con lo que tenemos introducido por vía de hecho y tendencialmente, el principio de igualdad ante la ley. De modo que complementariamente a la institucionalización del dinero como código de autogobierno del sistema económico y que se asienta sobre regulaciones de derecho privado, tenemos la introducción del código «poder» en el sentido weberiano de «dominación legal-racional» moderna. Y si el código «dinero» moderno se asienta sobre fundamentos legitimatorios obvios (posición simétrica de las partes contratantes o -al menos esta es la idea desde mediados del siglo XVIII en adelante- promesa de realización efectiva de la justicia en el intercambio de equivalentes, tal como esa equivalencia viene definida por el mercado, el código «poder» no se asienta a efectos legitimatorios sobre nada, es la resultante de los actos de la voluntad soberana o «es» la voluntad del soberano.

Conviene añadir dos cosas. En primer lugar, una precisión: las simplificaciones que he hecho en la descripción que precede son por supuesto excesivas, pero si es cierto que el orden social liberal no emerge de la rebelión contra las monarquías absolutas, sino que la «época de las revoluciones burguesas» es producto de la rebelión contra el Estado absoluto del orden social configurado en el seno de ese Estado y de la adaptación de él a ese orden. Pero por eso mismo, conviene añadir, y esta es la segunda cuestión a la que quiero referirme, que el Estado moderno gestado bajo la monarquía absoluta, con la acumulación de poder político, económico, militar (hacia el exterior) y de represión (hacia el interior) que comporta, con la capacidad de «información» y «surveillance» que es capaz de desarrollar, y con la «interiorización de la disculpa» que es capaz de desarrollar, y con la «interiorización de la disciplina» que es capaz de poner en marcha, representa el marco de referencia de la autocomprensión específica» de la modernidad política (tanto en su versión liberal como en su versión democrática), marco al que ambas tradiciones de pensamiento, por así decirlo, han tratado de dar alcance, cosa que, pese a todo, ambas han estado lejos de conseguir. No se trata aquí tanto de iniciar una consideración «a la Foucault» 
(que por otro lado no estaría de más), pero sí de hacerle justicia en este punto, sin que por ello haya en principio necesidad de reducir a su vez a "poder» la razón ético-política que ambas tradiciones han tratado de poner en ese marco ${ }^{13}$.

Segunda etapa: Es la etapa de la constitucionalización de los «derechos civiles» de Marshall. Las regulaciones del derecho privado, ampliadas o extrapoladas en su contenido, quedan elevadas a derechos subjetivo-públicos. No cobra el derecho su validez de la sanción del soberano, sino de un «orden natural» de derecho privado, no político («estado de naturaleza» de Locke) del que recibe su legitimidad el «government» (que no soberano) por el carácter instrumental que posee para la guarda de los supuestos jurídicos de un orden social capaz de regularse a sí mismo anónimamente con tal que se respete y se haga respetar su trama normativa; es decir, se da forma constitucional, recibe forma de derecho lo que en la etapa anterior se impone por vía de hecho, y el poder, antes enteramente «suelto», sólo se legitima ahora (se borra la asimetría señalada) por su carácter instrumental para la guarda de los supuestos jurídicos de un orden social que se muestra capaz de regularse a sí mismo, con tal que se respeten supuestos funcionales que tienen su traducción normativa en esos supuestos jurídicos; más aún, toda intervención en ese orden, aparte de injusta, lo desestabiliza. Ahora las personas privadas son portadores de unos derechos que pueden hacer valer frente a un soberano reducido a «government»; la garantía que representan los derechos lockeanos ya no pueden interpretarse como efectos funcionales de un sistema económico asentado sobre el derecho privado moderno, que recibiera su sanción del soberano, sino que al cobrar rango constitucional, su relación con el poder se invierte. Por lo demás, una vez que el soberano absoluto queda reducido a government, en rigor nunca fue problema urgente en la tradición liberal la cuestión de quien gobierna, sino de poner límites normativos estrictos (los derechos lockeanos) a un «poder» necesario por instrumental. Hayek lo expresa no sin cierto cinismo para oídos contemporáneos: «Lo opuesto a la democracia es el gobierno autoritario, lo opuesto al liberalismo es el totalitarismo. Ninguno de los dos sistemas excluye necesariamente el opuesto del otro: una democracia puede muy bien hacer uso de poderes totalitarios; y es al menos concebible que un gobierno autoritario pueda actuar asentando su política sobre principios liberales» ${ }^{14}$.

\footnotetext{
${ }^{13}$ Cfr. A. Gidden, National State and Violence, London, 1985.

${ }^{14}$ Hayek, New Studies, loc. cit., 143.
} 
Tercera etapa: institucionalización de los «derechos políticos el sentido de Marshall o primer compromiso entre la tradición de pensamiento liberal y la tradición de pensamiento democrático, o lo que es lo mismo: la creación del «hierro de madera» (tales compuestos, quizás por fortuna, son siempre políticamente posibles) que representa el «Estado democrático de Derecho». El soberano, que el principio liberal redujo a «government» queda ahora rehabilitado a la vez que democratizado; dicho de otro modo, el soberano es el pueblo. En conceptos de Rousseau, el soberano ha depuesto a quien, tiranizando a todos, se había constituido en «señor», y tiene al «government» como «príncipe». O expresado aún de otro modo: el poder del Estado limitado en la etapa anterior constitucionalmente queda ahora democratizado; ambas cosas que obedecen a principios distintos, van juntas en Francia; en «las Islas» la democratización del poder cercado por los derechos lockeanos se produce después; y aquí es donde habla Marshall de estado de guerra de los derechos políticos constitucionalizados, contra ámbitos de la existencia asentados sobre derechos civiles asimismo constitucionalizados. En Francia la guerra comienza en el momento mismo de la «Declaración de Derechos». Recordemos, ante todo, la anécdota; en la «Asamblea Nacional», durante la discusión del texto de la Declaración se produce un enfrentamiento entre los representantes inspirados por Locke y los representantes inspirados por Rousseau en lo tocante al título y también al contenido de la «Declaración de Derechos». Los primeros entienden que la Declaración ha de llevar el título de «Declaración de los Derechos del Hombre», los segundos de «Declaración de los Derechos del Ciudadano», por fin se llega a la fórmula de compromiso «Declaración de los Derechos del Hombre y del Ciudadano». Más allá de lo anecdótico, la anécdota es reveladora de los siguientes: se democratiza al poder que en la etapa anterior había quedado cercado constitucionalmente por la institucionalización del principio liberal. Pero la institucionalización del papel de ciudadano queda sometida en los «Estados democráticos de Derecho» al mismo cerco a que en los «Estados de Derecho» había quedado reducido el poder del soberano del absolutismo. Por supuesto que si tal compromiso entre principio liberal y principio democrático se produce, es que es posible, y ello incluso en una «declaración» como la francesa, en la que tras recogerse la fórmula de Rousseau de que la «ley es la expresión de la voluntad general»se declara «sagrado e inviolable» al derecho de propiedad. Tal posibilidad estriba en que los «derechos liberales» pueden interpretarse en sentido democrático como condiciones normativas del 
proceso de deliberación. Ahora bien, por más vueltas que se le dé, es difícil interpretar al derecho de propiedad en tales términos. Y el derecho de propiedad sobre los «medios de producción» no es «un derecho más», sino que significa nada más y nada menos que la diferenciación respecto del «sistema político» de un orden social, cual es el liberal, centrado en torno al sistema económico; y no cabe duda de que sobre tal diferenciación ha versado buena parte de la problemática e incluso de la aporética de las relaciones entre modernidad política y modernidad social, incluso hasta el presente. De modo que desde este primer compromiso las constituciones modernas (en las que directamente nacen de la revolución francesa es lo que sucede sin duda alguna) llevan en su seno dos piezas distintas, políticamente no compatibles y teoréticamente tampoco, de suerte que la tensión es constante y los compromisos frecuentes. Los dos principios conviven pacíficamente bajo el techo de una misma constitución mientras una economía de manufacturas pequeñas y medias parece confirmar el supuesto fáctico de la «promesa liberal». E incluso cabría decir, si olvidamos el Termidor francés, que el orden liberal puede convertirse en el contenido político de la «voluntad democrática» (así puede leerse la «Declaración de Virginia» de 1776). Pero desde mediados del siglo XIX esa promesa se hace cada vez más dudosa, hasta no quedar nada de ella hacia fines de los años veinte de este siglo. Sobre el trasfondo de esa historia social que omito (así como sobre las experiencias históricas que representan la derrota del fascismo y la dirección tomada por la revolución soviética), hay que entender la salida que representa el «Estado de Derecho, democrático y social», que es como define a España la Constitución Española de 1977.

Cuarta etapa: Destruido el orden liberal tras la crisis de los años treinta, el «Estado social» (el elemento que, si prescindimos de la Constitución de Weimar, se suma como novedad política al «Estado democrático de Derecho» en los países occidentales tras la segunda guerra mundial) hace frente constitucionalmente a las consecuencias de un sistema económico (y por consiguiente, de un orden social) que, como prácticamente había demostrado la crisis de 1929 y teoréticamente demuestra Keynes en 1936, no es capaz de estabilizarse a sí mismo. El «Estado social» es la nueva fórmula de compromiso entre el principio liberal y el principio democrático, en la que se mantiene la lógica del sistema económico asentado sobre el elemento liberal de las Constituciones, pero el Estado recibe el encargo de ponerle condiciones marginales para llevarlo a o, mantenerlo en, un punto de equilibrio aceptable, y al mismo tiempo de absorber o neutralizar los efectos de 
la relación de poder social o estructural inscrita en el sistema económico, que el liberalismo había ignorado. Las vagas fórmulas de «función social de la propiedad» o «economía social de la propiedad» o «economía social de mercado» vienen a atemperar el cerco que el principio liberal había puesto al principio democrático, pero que no lo rompen. La intervención del Estado en la economía (sobre la base del recetario keynesiano) tiene necesariamente que invocar principios democráticos, pero la intervención es en un ámbito de la vida social estructurado en términos de derecho privado, protegido por el elemento liberal de las constituciones, en un ámbito que se autogobierna por el código «dinero». Es decir, el medio «poder» interviene en una esfera de la vida social estructurada conforme a otra lógica, a la que ha de respetar, y que obliga a que lo que, según el principio democrático, habían de ser tratados como problemas políticos, sólo puedan serlo como problemas técnico-administrativos. En tal situación el Estado puede manipular las condiciones marginales de los procesos de decisión económica, pero ni puede disponer directamente de ellas ni forzar la intervención hasta un punto en que se torne disfuncional por desorganización de la lógica del sistema económico. De ahí que, por un lado, el «Estado social» como fórmula de compromiso entre el principio liberal y el principio democrático se convierta en «contenido político de la democracia de masas» (Habermas) a la vez que en él se cifra la «despolitización» del «pueblo soberano», y que, por otro, esos «derechos sociales» queden peculiarmente «sueltos» en las constituciones que nacen de la segunda guerra mundial, a cuya familia se suma la española. El artículo 53. 3. de la Constitución Española es buena prueba de lo que quiero decir con esta última afirmación.

Pues bien, esta fórmula de paz entre ambos principios es la que queda puesta en cuestión desde principios de los años setenta o incluso desde fines de los años sesenta desde dos lados. Por un lado, empiezan a hacerse visibles las disfuncionalidades que en los mecanismos de la integración social comienza a provocar la profundización de la intervención estatal en la vida de los «clientes» del «Estado social» («colonización del mundo de la vida», Habermas). Mas por otro, y este es, sin duda, el capítulo decisivo en la crisis del «Estado social», desde mediados de los años setenta desaparece uno de sus supuestos económicos: el de la eficacia de la intervención del Estado en la economía en términos keynesianos. Frôbel y su equipo describen la crisis económica de los años setenta recurriendo a dos factores que demostrarían su carácter estructural, es decir, que los supuestos sobre los que se asentaba el Estado Social son difícilmente reconstruibles. 
«La maquinaria de este compromiso en el período de ampliación tras la reconstrucción de las capacidades de producción destruidas, la ampliación del sector terciario, la incorporación de las mujeres a la producción, la disminución de la jornada laboral, el aumento del nivel de expectativas al convertirse los programas del Estado social en contenido político de la democracia de masas, y ello en el contexto de la competencia de partidos y de una rotación de las élites políticas, llevan por un lado a la homogeneización de la mano de obra y por otro a un reforzamiento de la posición negociadora de las organizaciones sindicales. Todo ello empieza a hacer algunas industrias poco rentables, pues conduce a una disminución general de la tasa de beneficios. Dos formas había de ajustar la oferta de mano de obra a una tasa de beneficios que cupiese considerar aceptable: la primera reducir temporalmente las inversiones; la segunda invertir, pero en medios de racionalización que permitiesen la reducción de mano de obra. Pero mientras tanto funcionó un factor externo, que condujo desde fines de los años sesenta a una «nueva división internacional del trabajo». Se torna posible reorganizar la producción industrial fragmentando esa producción y repartiendo los fragmentos en zonas donde pudiera encontrarse una mano de obra barata y disciplinada y además subvencionada en parte por la existencia de medios no industriales; es decir, que para una serie de producciones, la ventaja de estar ubicadas en los países industriales no compensaba los costes. El funcionamiento conjunto de ambos factores da lugar a mediados de los años setenta a una crisis cuya causa central resume Frôbel en los siguientes términos: «El modelo de compromiso social basado en un aumento de los salarios de acuerdo con la productividad no podía considerarse a la larga como un modelo de acumulación creciente y autocentrada, sostenible a la larga en los países industriales, ya que las relaciones aparentemente residuales de los países centrales con su entorno mundial, sobre todo con el capitalismo periférico de los países en desarrollo, más tarde o más temprano tenían que privar a ese modelo, a través de mecanismos de racionalización o desplazamiento, de uno de los presupuestos centrales de su funcionamiento: de su carácter cerrado» ${ }^{15}$. Y por su parte, C. Offe plantea el dilema a que ello da lugar, en unos términos que se han vuelto clásicos: «La primera conclusión que podemos sacar de este tipo de análisis es que el

${ }^{15}$ Froebel, F., et. al., La nueva dimensión internacional del trabajo, México, 1977. 
Estado social no es una fuente autónoma de bienestar que pusiera a punto ingresos y prestaciones como un derecho ciudadano, sino que dependió en buena parte de la prosperidad y rentabilidad de la economía. El Estado social fue proyectado como remedio frente a algunas enfermedades de la acumulación, pero el tipo de enfermedad puede llevar al paciente a abandonar la cura... El penoso misterio del Estado social es el siguiente: es posible que sus efectos sobre la economía empiecen a ser destructivos, pero su eliminación sería explosiva (y es el hecho que ignora el análisis conservador). Lo que esto nos revela es que el capitalismo ni puede prescindir del Estado social ni puede pervivir con él. En la posguerra los países occidentales lograron dominar este dilema, pero hoy este dilema parece haberse vuelto contradicción. El compromiso ha perdido el punto en que el Estado social podía funcionar como elemento política y económicamente estabilizador» ${ }^{16}$.

\section{IV}

\section{Sobre «la virtud y el curso del mundo»}

En una recensión aparecida como artículo de prensa de un libro colectivo que tiene como temas centrales la obra de Habermas y la obra de Foucault, el recensionista concluye con las siguientes palabras: «Hölderlin y Heidegger buscaban una salvación global de un peligro local. Los autores que comentamos (los críticos de Foucault, que recurren a Habermas) buscan la salvación local de un peligro global. No intentan salvarnos del peligro, intentan salvar el peligro: cambiando las cosas lo necesario para que sigan igual.» No deja de ser sorprendente que la irrupción de lo absolutamente nuevo en la historia, la Revolución con letras mayúsculas, no pueda pensarse hoy sino en términos quietistas y «posmodernos», y, quién lo diría, nada menos que de la mano de Hölderlin y Heidegger. Es por tanto el momento de recurrir a Marx, una vez liberados de afanes revolucionarios, pues es quizá entonces cuando Marx puede resultar más instructivo. Para ello, claro está, es menester despedirse de una «virtud» revolucionaria que sólo deja pensarse de la mano de Hölderlin y Heidegger, y darse un tanto al curso del mundo.

\footnotetext{
${ }^{16}$ C. Offe, Arbeitsgesellschaft. Strukturprobleme und Zukunfsperspektiven, Frankfurt, 1984, págs. 327.
} 
Y el mundo, el mundo occidental al menos, si prescindimos por un momento de su periferia y semiperiferia, ha logrado estabilizarse en los últimos cuatro o cinco años en términos «neoliberales». La crisis de un sistema económico mundializado parece de nuevo superada; no se sabe por cuanto tiempo ni parecen importar mucho en Occidente las consecuencias inducidas en la «periferia». Por supuesto que durante la crisis nadie pensó en una «transición al socialismo real»; tras ella, muy al contrario, es en los países del «socialismo real» donde parecen al menos correr aires de «transición al capitalismo» (la expresión puede oírse en la Centroeuropa socialista). Incluso el brutal ajuste a las condiciones de tal economía mundializada, que con evidente éxito ha llevado a cabo en nuestro país un gobierno socialista en las condiciones de una «democracia liberal» recién estrenada comienza a verse en Centroeuropa (pese a la casi definitiva instauración de una sociedad de «dos tercios», que a la larga acabará haciendo preciso una reinstauración del Estado social semidesmontado apenas construido, ¿en forma quizá de un nuevo florecimiento de las instituciones benéficas de tipo privado, como parece sugerir Nozick?) como un modelo, si no quizás a seguir, sí al menos envidiado, una vez destruido el sueño de una economía cerrada, ante la nueva hornada de acumulación y tecnología que se avecina, que cada vez tiene menos que ver con el «trabajo en general», «trabajo abstracto», «travail sans phrase», que saludaba Marx en el sistema económico como realidad y en la teoría económica moderna como categoría y sí con flujos de información y capital a nivel mundial.

Lo que en la sección anterior he reconstruido como tensión, choque y recíproca limitación de dos autocomprensiones de la modernidad política, también puede reconstruirse en otros términos, a saber: como una superación (Aufhebung) del principio liberal en el principio democrático, y ello como «un siempre ya superado» (Hegel) o en el sentido de una superación revolucionaria del principio liberal en el principio democrático (Marx). Consideremos brevemente la estructura de la «Filosofía del Derecho» de Hegel. Como «Derecho abstracto» Hegel construye en lo esencial lo que he llamado «contenido normativo» de la tradición liberal, sin lo que he llamado su «supuesto fáctico», que en el capítulo sobre «la sociedad civil», recurriendo a Malthus, Hegel pone parcialmente en cuestión. (Es por lo demás este recurso a Malthus el que en los párrafos 245-256 de la «Filosofía del Derecho» permite leer tanto a Marx como a Keynes).

El capítulo sobre «la Eticidad» está construido desde la experiencia de la destrucción del síndrome que religión, política, derecho 
«puesto» por el príncipe, costumbres y economía forman en los mundos de la vida tradicionales; desde la experiencia, pues, de la ruptura que, con la emergencia de la sociedad moderna, experimentan en los «mundos de la vida» históricos o tradicionales las solidaridades e identidades colectivas sostenidas por ese síndrome.

La «sociedad civil», lo único que la tradición liberal conoce (con el apéndice del «government»), como bien se queja Hegel, queda entendida por éste como destrucción de la esfera de comunidad, conforme a categorías de un derecho privado elevado a derecho público que acaban disolviendo aquel síndrome, o dicho en otros términos: como eclosión de un elemento sistémico («sistema de las necesidades»), que es «lo ético roto y extrañado de sí»; la «bella totalidad» de la polis griega escindida en dos extremos, el de un individuo que en la sociedad moderna pierde suelo, «patria», sustancia y elementos de identificación y el de una totalidad relacional (el sistema económico) sujeta a leyes que semejan leyes de la naturaleza.

Ahora bien, «por su propia dinámica interna», es decir, movida por las propias disfunciones que genera el sistema económico, la «sociedad civil», el mundo liberal se ve llevado más allá de sí mismo: «como esta determinada sociedad» y «como tal sociedad». «Como esta determinada sociedad ${ }^{17}$, es decir, como mundo liberal occidental moderno, este mundo está llamado por su propia dinámica interna a difundirse y a transformar a su imagen y semejanza toda sociedad que no esté a su altura. «Como tal sociedad» la «sociedad civil» se ve llevada al «Estado». El tipo de identidad colectiva (la identidad nacional) que el Estado constitucional moderno logra articular en torno a sí y que sirve de sostén a lo inorgánico de la sociedad civil es interpretado por Hegel como la «sustancia», la «voluntad general» en su interpretación sustancialista, como reconstrucción de la «eticidad», como una «comunidad» que en la articulación que le da el Estado constitucional está a la altura de los tiempos, «hace justicia a todos los momentos de la idea», que ciertamente permite el desarrollo y el movimiento omnímodo de la individualidad en el contexto de la «sociedad civil», pero que como Estado nacional se yergue frente a ella como instancia superior sin desprenderse de la «particularidad» de las formas de vida históricas. Esta exaltación de la particularidad nacional que el Estado (pese a su elemento universalista como Estado constitucional) representa, sólo deja realizarse a lo universal en la dinámica misma de la

${ }^{17}$ Cfr. Hegel, Filosofía del Derecho, par. 246 ss. 
historia universal; lo universal completo sólo se realiza por encima de la cabeza de los individuos y de los Estados y sólo puede ser demostrado por la filosofía, que a la vez muestra a los ciudadanos la razón del Estado en su particularidad de Estado nacional. De la estructura de la «Filosofía del Derecho» de Hegel parte la crítica de Marx.

El Estado que Hegel ha pensado no es lo que dice ser: superación de la «sociedad civil», reconstrucción de un «mundo ético» a la altura de los tiempos, de un mundo ético que hace justicia a todos los momentos de la idea, sino apéndice de una sociedad civil asentada sobre la supresión y abstracción de toda esfera de comunidad. También en Marx esta sociedad se ve llevada más allá de sí misma. «Como esta determinada sociedad» está llamada como cuestión de hecho (hecho que valorativamente hay que celebrar, pues frente a los mundos tradicionales la «sociedad civil» encierra un principio a la altura de los tiempos, representa la plasmación histórica de una razón superior) a eliminar toda forma de vida histórica que no esté a su altura (cfr. las primeras páginas del «Manifiesto Comunista»). «Como tal sociedad» se ve también «empujada más allá de sí misma», pues que genera en su seno su propia negación (la clase ligada al «trabajo», que queda excluida de los beneficios económicos, jurídicos y «espirituales» (culturales) de la sociedad civil).

Ahora bien, tal esfera de comunidad que finalmente haga en verdad justicia a todos los momentos de la Idea no puede entenderse sino como situada al final de un proceso revolucionario en el que la cuasinaturaleza que representa un sistema económico mundializado, el cual instrumentaliza a todos y a todo, pueda ser suprimida una vez consumada; sólo entonces el hombre universal, pero atomizado, de la «sociedad civil» podrá reabsorber en sí al ciudadano abstracto de Hegel; y sólo entonces puede quedar consumada la promesa de la tradición democrática.

Y así, tenemos la grandiosa y a la vez ambivalente idea de una irrupción cuasimesiánica de lo nuevo a nivel mundial, en la que la fundación de una indefinida comunidad moral «a la Rousseau», la superación en una libertad moral de la libertad natural que liga al hombre a los imperativos de una dinámica social convertida en un proceso cuasinatural puede interpretarse como fin de la prehistoria y comienzo de la verdadera historia, de la historia que los hombres puedan hacer autónomamente, es decir, con voluntad y conciencia. Mas en toda esta visión la distancia entre arbitrio individual y voluntad racional crece o puede crecer hasta el infinito, crece o puede crecer hasta el infinito el tramo en que también en la tradición democrática sólo 
anida el ciego hecho del poder. Es la versión que a la teoría marxista de la revolución da Lenin, la apelación a la promesa de la tradición democrática se convierte en elemento legitimatorio de un orden político en el que difícilmente cabe reconocer elemento alguno del núcleo normativo de esa tradición, si no es evaporado en «metafísica». Pero aquí no es este nuestro problema.

Lo que la construcción de Hegel saca a la luz es una falla de todo el iusnaturalismo moderno: la incapacidad de distinguir entre Estado y sociedad. Ni la tradición liberal ni la tradición democrática pueden entender de otro modo la sociedad que como orden o cuerpo político. Es Hegel el primero que logra romper el esquema de la tradición y dar razón de la novedad de la modernidad social como proceso de diferenciación de un orden social centrado en torno al sistema económico, respecto de un orden de lo político que en Hegel, eso sí, queda dotado de todos los atributos de la Polis antigua. Pues bien, es Marx, al criticar la idea hegeliana de la superación ya siempre realizada de la sociedad civil en el Estado, el primero en desnudar al Estado de toda aura normativa, en rebajarlo a «subsistema político» de un orden social, entregando el estudio de su estructura no a una teoría política normativa sino a las ciencias sociales, a la vez que desliga de él a la idea democrática desplazándola hacia un medio indefinido. En todo caso, la realización de esa idea, implica para Marx un proceso de desdiferenciación en la modernidad social, una restitución de la sociedad a un ámbito de lo político vislumbrado en términos organizativos ajenos a los del Estado nacional moderno y los de la economía moderna. La cuestión de si en un futuro ello será así o no, de si en las circunstancias presentes cabe pensar en tamaño proceso de desdiferenciación, y de qué aspecto podría tener el resultado de tal proceso de diferenciación, no es ya hoy cuestión de una «teoría de la revolución», sino de arriesgada futurología, que probablemente quedase desmentida mañana.

\section{V}

De vuelta al problema de una teoría de los derechos fundamentales. Reivindicación del núcleo normativo de la tradición democrática

Hoy hemos de partir de un sistema económico internacionalizado, asentado ciertamente sobre regulaciones de derecho privado, 
pero que hace mucho que se yergue sobre toda discusión acerca de derechos de propiedad. De un sistema político en el que la ficción que siempre fue el soberano se ha evaporado, cuyas intervenciones en el sistema económico apenas alcanzan para ajustar las economías nacionales a los imperativos de la economía mundializada, y cuyos órganos deliberativos más que institucionalización del núcleo normativo de la tradición democrática hay más bien que entenderlos como escena de pugna, negociación y compromiso entre grupos capaces de generar orden social o como lugar de legitimación de tales compromisos, de modo que por un lado el sistema político en ejercicio aparece como un poder social más, pero del que dimanan las decisiones colectivamente vinculantes. Un sistema jurídico, con su propia lógica, desde luego, pero que es el medio de realización de programas políticos y que se haya desbordado e incluso desorganizado por la necesidad de atender a imperativos contradictorios. Y ello en el medio de una opinión pública, siempre fragmentada, pero en la que se solapan lo nacional y lo internacional, es decir, que va más allá del colectivo para el que vale un sistema jurídico. Y de una formación de identidades colectivas, que cada vez se centran menos en torno al Estado nacional, sino que o bien lo superan o bien le vuelven las espaldas con el riesgo de quedar despojadas del elemento universalista, que pese a su particularismo el Estado constitucional también contiene, o ambas cosas a la vez.

Pues bien, en la medida en que en los capítulos de las constituciones, relativos a derechos fundamentales se definen elementos de la trama normativa de ámbitos de la existencia, que el sistema político tiene el encargo de proteger y que a la vez significan un deslinde frente a él, o las reglas de juego que rigen en el sistema político en la medida en que ciertos aspectos de la generación de orden social pasan por la toma de decisiones colectivamente vinculantes por vía de derecho, ¿es posible una teoría unitaria y consistente de esos capítulos?

Hasta aquí he venido contando una historia para hacer plausible una respuesta negativa. Pero tal historia no basta si se tiene presente que la amalgama de lo producido por tales principios es tal, que difícilmente la tradición liberal o la tradición democrática, al menos en su forma clásica, podrían reconocerse en la realidad política presente.

Por lo demás, cuando la teoría del Estado comenzó a hacerse imposible «teoría política normativa», fue el positivismo jurídico quien con su doble idea de que las cuestiones prácticas (de ética política) no son susceptibles de verdad y de que es posible una 
ciencia del derecho como fenómenos pertenecientes a la esfera del «deber ser» desarrolla una teoría «científica» del Estado, en la que elementos de ambas tradiciones son reducidos a una teoría jurídica unitaria, también en lo tocante a Derecho Constitucional, y lo que en ella no cabe queda arrojado fuera como ideológico o al menos como algo que nada tiene que ver con él ni con el Derecho ni con la Ciencia del Derecho. Parto, pues, de aquí y vuelvo al libro de R. Alexy.

Mi tesis frente a Alexy va a ser la siguiente. No es posible una teoría unitaria y consistente de los capítulos sobre derechos fundamentales porque tal teoría sólo podría adoptar, en efecto, la forma de una teoría de la «Abwägung der Prinzipien» (ponderación de principios), pero tal «Abwägung der Prinzipien» no es una cuestión teorética sino política. Y si ello es así, nos vemos en la siguiente alternativa: o bien tal Abwägung se hace conforme a unos criterios de ponderación o sistema de valores arbitrarios (también jurídicamente, en el sentido de no definidos en la propia Constitución), o son objeto de validación pública, y ello sólo puede tener lugar en espacios de discusión pública de los que quepa afirmar cumplen, al menos mínimamente, los supuestos normativos de la tradición democrática. Si esto último no es posible, sólo queda la primera alternativa: la de un sistema de valores arbitrario.

Vayamos por partes. Como bien señala Alexy, una teoría de los capítulos de derechos fundamentales de una Constitución tiene que empezar siendo una teoría jurídica de los derechos fundamentales positivados en esa Constitución, por tanto, una teoría de un fragmento de derecho positivo de un determinado ordenamiento jurídico, es decir, una dogmática.

Y en una dogmática jurídica podemos distinguir tres dimensiones, una analítica, otra empírica y otra normativa. En la analítica se trata de la ordenación conceptual y sistemática de esa parte del derecho vigente. El espectro de tareas va desde el análisis de conceptos básicos hasta la investigación de la estructura de ese fragmento de ese sistema jurídico y de la relación de esa estructura con la estructura de todo el ordenamiento. La dimensión empírica de la dogmática jurídica ofrece un doble aspecto, el relativo al conocimiento mismo del derecho vigente y el relativo al empleo de premisas empíricas en la argumentación jurídica. «En la tercera dimensión, la dimensión normativa, se trata de la orientación hacia, y de la crítica de, la praxis judicial. Para esta dimensión es esencial la cuestión de cuál es en cada caso la decisión concreta y correcta partiendo del derecho vigente. En todos los casos dudosos la respuesta a esta pregunta incluye valoraciones 
por parte del que pregunta. La dogmática jurídica, sobre todo en esta dimensión, es en buena medida, la tentativa de dar respuestas racionalmente fundadas a las cuestiones dejadas abiertas por el material jurídico de que se parte» ${ }^{18}$.

$\mathrm{Y}$, ¿cómo articular esas respuestas racionalmente fundadas a las cuestiones dejadas abiertas por el material jurídico? La respuesta obviamente es: la dogmática ha de contener también una teoría material de los derechos fundamentales, consistente, unitaria y consistente (por supuesto) con el material jurídico. Esta teoría (jurídica) material de los derechos fundamentales «hay que fundamentarla recurriendo a la letra de la Constitución, a la voluntad del legislador, a la jurisprudencia del tribunal constitucional..., pero como tales teorías son siempre algo más que simples repeticiones de la letra de la Constitución, de la voluntad del legislador y de la jurisprudencia constitucional averiguables empíricamente, no pueden apoyarse directamente ni en la autoridad de la Constitución ni directamente en la autoridad de la jurisprudencia constitucional... Constitución, jurisprudencia y dogmática constituyen una línea de autoridad claramente decreciente. Una teoría material de los derechos fundamentales tiene el carácter de una base de la argumentación relativa a esos derechos, no dotada de autoridad, sino apoyada argumentativamente. Ahora bien, el concepto de una base de la argumentación apoyada argumentativamente se expone a la objeción de circularidad. Pero a esta objeción se le puede hacer frente con ayuda de una distinción entre base y proceso. La idea de que en el curso de la argumentación se esté suponiendo una teoría, que sea susceptible de refutación, pero que mientras no quede refutada, constituye una base para ulteriores argumentaciones, no tiene nada de circular. La cuestión es entonces qué aspecto tiene tal teoría y cómo puede contribuir al control racional de la argumentación sobre derechos fundamentales» ${ }^{19}$. Con ello, aun partiendo de las posiciones del positivismo jurídico, y sin necesidad de contar historias, volvemos a dar en la tesis que venimos sugiriendo.

Pues Alexy, obviamente, tras hacer esa pregunta no tiene más remedio que recurrir al ya clásico trabajo de Böckenförde ${ }^{20}$. Böckenförde distingue cinco teorías posibles: la liberal, la institucional tipo Hauriou y Romano y renovada en Alemania por

${ }^{18}$ R. Alexy, Theorie der Grundrechten, Frankfurt, 1986, pág. 22.

${ }^{19}$ Ibíd., pág. 509.

${ }^{20}$ E. W. Böckenförde, «Grundrechtstheorien und Grundrechtsinterpretation», en NJW, 1529 ss. 
Haberle, la teoría de los derechos fundamentales como valores, la democrática (hoy por ejemplo tipo Ely ${ }^{21}$ ) y la «sozialstaatliche» (si fuera posible considerarla como independiente de la liberal y la democrática, que pienso que no). Para el propio Alexy, la institucional se reduce a la de los valores, y es por esta última por la que (como buen jurista alemán, próximo al Tribunal Constitucional de su país) opta Alexy. Aceptemos esta opción, pues se diría que incluso viene sugerida por el artículo 1. 1. de la propia Constitución Española, según el cual «España se constituye en un Estado social y democrático de Derecho, que propugna como valores superiores de su ordenamiento jurídico la libertad, la justicia, la igualdad y el pluralismo político». Quedan entonces como alternativas posibles la teoría liberal, la teoría democrática y la teoría de los valores.

El problema es, como encuentra el propio Böckenförde para el caso de la Grundgesetz alemana (y como sería bien fácil mostrar para la Constitución Española, con lo cual el citado artículo, en lo que a su mención de valores se refiere, resulta más hueco y aun superfluo) y de la jurisprudencia constitucional alemana, que la teoría que se elige sirve de base para la argumentación posterior mientras se mantiene en un determinado tramo de la Constitución, pero queda refutada en cuanto pasa a otro. Y el caso es que lo mismo ocurre con la jurisprudencia constitucional: los jueces aplican ya una teoría ya otra. «De ello no se sigue -comenta Alexy- que a la jurisprudencia constitucional no subyazga una teoría. El concepto de teoría de los derechos fundamentales no se limita a teorías que sólo hagan valer un principio, sino que puede haber una teoría de los derechos fundamentales que parta de una pluralidad de principios» ${ }^{22}$. Es justo esto lo que lleva a Alexy a optar a convertir tales principios en valores y a pensar en una teoría de la «Abwägung» racional de valores o entre valores (es decir, entre principios de la Constitución, históricamente provenientes de fuentes muy distintas y con significados distintos y aun contrarios). Sin embargo, acaba el libro y vemos debatirse y perderse a Alexy en el intento de explicarnos qué puede ser eso de una teoría de la «Abwägung» racional entre valores. A mi juicio, no existe tal teoría que proporcione un procedimiento para efectuar tal «ponderación». Tal ponderación habría de tener lugar, si acaso, en el seno de la opinión pública política, en el seno de la opinión pública jurídica, etc. (en el parlamento es más bien improbable, ignoro cómo

${ }^{21}$ J. H. Ely, Democracy and Distrust, Harvad, 1980.

${ }^{22}$ R. Alexy, ibid., 516. 
suceden las cosas en el Tribunal Constitucional) y las instituciones a las que compete decidir habrían de dejarse filtrar por tal discusión, de modo que la decisión resultante se haya producido en condiciones tales que, al menos presuntivamente, permitan calificarla de racional. Pero esto suena a «núcleo normativo de la tradición democrática». Si ello es así (en contra de la radicalización de la tradición liberal por Nozick, a la que en modo alguno se puede negar en la actualidad su evidente valor al menos descriptivo) se trata de una modestísima Aufhebung de la tradición liberal en la tradición democrática. Y me temo que hoy no cabe esperar mucho más (quizá mañana quepa esperar más o tal vez menos). 